In the format provided by the authors and unedited.

\title{
A global perspective on the trophic geography of sharks
}

Christopher S. Bird ${ }^{1,71 \star}{ }^{\text {, Ana Veríssimo }}{ }^{2,3}$, Sarah Magozzi', Kátya G. Abrantes ${ }^{4}$, Alex Aguilar ${ }^{5}$, Hassan Al-Reasi ${ }^{6}$, Adam Barnett ${ }^{4}$, Dana M. Bethea ${ }^{7,72}$, Gérard Biais ${ }^{8}$, Asuncion Borrell ${ }^{5}{ }^{5}$, Marc Bouchoucha ${ }^{9}$, Mariah Boyle ${ }^{10}$, Edward J. Brooks ${ }^{11}$, Juerg Brunnschweiler ${ }^{12}$, Paco Bustamante ${ }^{13}$, Aaron Carlisle ${ }^{14}$, Diana Catarino ${ }^{15}$, Stéphane Caut ${ }^{16}$, Yves Cherel ${ }^{17}$, Tiphaine Chouvelon ${ }^{18}$, Diana Churchill19, Javier Ciancio ${ }^{20}$, Julien Claes ${ }^{21}$, Ana Colaço ${ }^{15}$, Dean L. Courtney ${ }^{22,73}$, Pierre Cresson ${ }^{23}$, Ryan Daly ${ }^{24,25}$, Leigh de Necker ${ }^{26}$, Tetsuya Endo ${ }^{27}$, Ivone Figueiredo ${ }^{28}$, Ashley J. Frisch ${ }^{29}$, Joan Holst Hansen ${ }^{30}$, Michael Heithaus ${ }^{31}$, Nigel E. Hussey ${ }^{32}$, Johannes litembu ${ }^{33}$, Francis Juanes ${ }^{34}$, Michael J. Kinney ${ }^{35}$, Jeremy J. Kiszka ${ }^{36}{ }^{36}$, Sebastian A. Klarian ${ }^{37}$, Dorothée Kopp ${ }^{38}$, Robert Leaf ${ }^{39}$, Yunkai Lii ${ }^{40}$, Anne Lorrain ${ }^{41}$, Daniel J. Madigan ${ }^{42}$, Aleksandra Maljkovićc ${ }^{43}$, Luis Malpica-Cruz ${ }^{44}$, Philip Matich ${ }^{45,46}$, Mark G. Meekan ${ }^{47}$, Frédéric Ménard ${ }^{48}$, Gui M. Menezes ${ }^{15}$, Samantha E. M. Munroe ${ }^{49}$, Michael C. Newman ${ }^{50}$, Yannis P. Papastamatiou ${ }^{51,52}$, Heidi Pethybridge ${ }^{53}$, Jeffrey D. Plumlee ${ }^{54,55}$, Carlos Polo-Silva ${ }^{56}$, Katie Quaeck-Davies', Vincent Raoult $\mathbb{1}^{57}$, Jonathan Reum ${ }^{58}$, Yassir Eden Torres-Rojas ${ }^{59}$, David S. Shiffman ${ }^{60}$, Oliver N. Shipley ${ }^{61}$, Conrad W. Speed ${ }^{47}$, Michelle D. Staudinger ${ }^{62,63}$, Amy K. Teffer ${ }^{64}$, Alexander Tilley $\mathbb{1}^{65}$, Maria Valls ${ }^{66}$, Jeremy J. Vaudo ${ }^{67}$, Tak-Cheung Wai ${ }^{68}$, R. J. David Wells ${ }^{54,55}$, Alex S. J. Wyatt ${ }^{69}{ }^{6}$ Andrew Yool ${ }^{70}$ and Clive N. Trueman ${ }^{1 \star}$ 
${ }^{1}$ Ocean and Earth Science, University of Southampton, National Oceanography Centre, Southampton, UK. ${ }^{2} \mathrm{CIBIO}-$ Research Center in Biodiversity and Genetic Resources, Vairão, Portugal. ${ }^{3}$ Virginia Institute of Marine Science, Gloucester Point, VA, USA. ${ }^{4}$ College of Science \& Engineering, James Cook University, Cairns, Queensland, Australia. ${ }^{5}$ RBBio, Department of Evolutionary Biology, Ecology and Environmental Sciences, University of Barcelona, Barcelona, Spain. ${ }^{6}$ Department of Biology, College of Science, Sultan Qaboos Univeristy, Muscat, Oman. ${ }^{7}$ NOAA, National Marine Fisheries Service, Southeast Fisheries Science Center, 3500 Delwood Beach Road, Panama City, FL, USA. ${ }^{8}$ Ifremer, Unité Halieutique Gascogne Sud, Laboratoire Ressources Halieutiques de La Rochelle, L'Houmeau, France. 'Ifremer, Unité Littoral, Laboratoire Environnement Ressources Provence Azur Corse, La Seyne sur Mer, France. ${ }^{10}$ FishWise, Santa Cruz, CA, USA. "Shark Research and Conservation Program, Cape Eleuthera Institute, Eleuthera, Bahamas. ${ }^{12}$, Gladbachstrasse 60, Zurich, Switzerland. ${ }^{13}$ Littoral Environnement et Sociétés (LIENSs), UMR 7266, CNRS-Université de La Rochelle, La Rochelle, France. ${ }^{14}$ Hopkins Marine Station of Stanford University, Pacific Grove, CA, USA. ${ }^{15}$ MARE-Marine and Environmental Sciences Centre, Department of Oceanography and Fisheries, University of the Azores, Azores, Portugal. ${ }^{16}$ Estación Biológica de Doñana, Consejo Superior de Investigationes Científicas (CSIC), Sevilla, Spain. ${ }^{17}$ Centre d'Etudes Biologiques de Chizé, UMR 7372, CNRS-Université de La Rochelle, Villiers-en-Bois, France. ${ }^{18}$ Unité Biogéochimie et Ecotoxicologie, Laboratoire de Biogéochimie des Contaminants Métalliques, Nantes, France. ${ }^{19}$ Marine Sciences Program, School of Environment, Arts and Society, Florida International University, North Miami, FL, USA. ${ }^{20}$ CESIMAR Centro Nacional Patagónico, CONICET (Consejo Nacional de Investigaciones Científicas y Técnicas), Puerto Madryn, Chubut, Argentina. ${ }^{21}$ Laboratoire de Biologie Marine, Earth and Life Institute, Université Catholique de Louvain, Louvain-la-Neuve, Belgium. ${ }^{22}$ College of Fisheries and Ocean Sciences, Juneau Center, University of Alaska Fairbanks, Point Lena Loop Road, Juneau, AK, USA. ${ }^{23}$ Ifremer, Unité Halieutique Manche Mer du Nord, Laboratoire Ressources Halieutiques de Boulogne, Boulogne-sur-Mer, France. ${ }^{24}$ Port Elizabeth Museum at Bayworld, Port Elizabeth, South Africa. ${ }^{25}$ Save Our Seas Foundation-D'Arros Research Centre (SOSF-DRC), Geneva, Switzerland. ${ }^{26}$ University of Cape Town, Department of Biological Sciences, Cape Town, South Africa. ${ }^{27}$ School of Pharmaceutical Sciences, Health Sciences University of Hokkaido, Hokkaido, Japan. ${ }^{28}$ Departamento do Mar IPMA, Lisbon, Portugal. ${ }^{29}$ Reef HQ, Great Barrier Reef Marine Park Authority, Townsville, Queensland, Australia. ${ }^{30}$ Aquatic Biology, Department of Bioscience, Aarhus University, Aarhus C, Denmark. ${ }^{31}$ School of Environment, Arts, and Society, Florida International University, North Miami, FL, USA. ${ }^{32}$ Biological Sciences, University of Windsor, Windsor, Canada. ${ }^{33}$ Department of Fisheries and Aquatic Sciences, University of Namibia, Henties Bay, Namibia. ${ }^{34}$ Department of Biology, University of Victoria, Victoria, British Columbia, Canada. ${ }^{35}$ Ocean Associates, Inc., Southwest Fisheries Science Center, National Marine Fisheries Service, National Oceanic and Atmospheric Administration, La Jolla, CA, USA. ${ }^{36}$ Marine Sciences Program, Department of Biological Sciences, Florida International University, North Miami, FL, USA. ${ }^{37}$ Centro de Investigacion para la Sustentabilidad, Facultad de Ecologia y Recursos Naturales, Universidad Andres Bello, Santiago, Chile. ${ }^{38}$ Ifremer, Unité Sciences et Techniques Halieutiques, Laboratoire de Technologie et Biologie Halieutique, Lorient, France. ${ }^{39}$ Division of Coastal Sciences, University of Southern Mississippi, Ocean Springs, MS, USA. ${ }^{40}$ College of Marine Sciences, Shanghai Ocean University, Shanghai, China. ${ }^{41}$ Institut de Recherche pour le Développement (IRD), R 195 LEMAR, UMR 6539 (UBO, CNRS, IRD, IFREMER), Nouméa, New Caledonia. ${ }^{42}$ Harvard University Center for the Environment, Harvard University, Cambridge, MA, USA. ${ }^{43}$ Department of Biological Sciences, Simon Fraser University, Burnaby, British Columbia, Canada. ${ }^{44}$ Earth to Ocean Research Group, Department of Biological Sciences, Simon Fraser University, Burnaby, British Columbia, Canada. ${ }^{45}$ Marine Sciences Program, Florida International University, North Miami, FL, USA. ${ }^{46}$ Texas Research Institute for Environmental Studies, Sam Houston State University, Huntsville, TX, USA. ${ }^{47}$ Australian Institute of Marine Science, Indian Ocean Marine Research Centre, The University of Western Australia, Perth, Western Australia, Australia. ${ }^{48}$ Mediterranean Istitute of Oceanography (MIO), Aix Marseille Université, Université de Toulon, CNRS, IRD, 13288 Marseille, France. ${ }^{49}$ Australian Rivers Institute, Griffith University, Nathan, Queensland, Australia. ${ }^{50}$ Department of Environmental and Aquatic Animal Health, Virginia Institute of Marine Science, College of William \& Mary, Gloucester Point, VA, USA. ${ }^{51}$ Department of Biological Sciences, Florida International University, North Miami, FL, USA. ${ }^{52}$ Scottish Oceans Institute, School of Biology, University of St. Andrews, St. Andrews, UK. ${ }^{53} \mathrm{CSIRO}$ Oceans and Atmosphere, Hobart, Tasmania, Australia. ${ }^{54}$ Department of Marine Biology, Texas A\&M University at Galveston, Galveston, TX, USA. ${ }^{55}$ Department of Wildlife and Fisheries Sciences, Texas A\&M University, College Station, TX, USA. ${ }^{56}$ Facultad de Ciencias Naturales e Ingeniería, Programa de Biología, Universidad de Bogotá Jorge Tadeo Lozano Marina, Bogotá, Colombia. ${ }^{57}$ Department of Environmental and Life Sciences, University of Newcastle, Newcastle, New South Wales, Australia. ${ }^{58}$ Conservation Biology Division, Northwest Fisheries Science Center, National Marine Fisheries Service, National Oceanic and Atmospheric Administration, Seattle, WA, USA. ${ }^{59}$ Instituto de Ecología, Pesquerías y Oceanografía del Golfo de México (EPOMEX), Universidad Autónoma de Campeche (UAC), Campeche, Campeche, Mexico. ${ }^{60}$ Earth to Oceans Group, Department of Biological Sciences, Simon Fraser University, Burnaby, British Columbia, Canada. ${ }^{61}$ School of Marine and Atmospheric Sciences, Stony Brook University, Stony Brook, NY, USA. ${ }^{62}$ Department of Environmental Conservation, University of Massachusetts Amherst, Amherst, MA, USA. ${ }^{63}$ Department of the Interior Northeast Climate Science Center, Amherst, MA, USA. ${ }^{64}$ Department of Biology, University of Victoria, Victoria, British Columbia, Canada. ${ }^{65}$ WorldFish Timor-Leste, Dili, Timor-Leste. ${ }^{66}$ Instituto Español de Oceanografía, Centre Oceanogràfic de les Balears, Palma, Spain. ${ }^{67}$ The Guy Harvey Research Institute, Nova Southeastern University, Dania Beach, FL, USA. ${ }^{6}$ State Key Laboratory in Marine Pollution, City University of Hong Kong, Kowloon, Hong Kong, China. ${ }^{69}$ Department of Chemical Oceanography, Atmosphere and Ocean Research Institute, The University of Tokyo, Kashiwa, Japan. ${ }^{70}$ National Oceanography Centre Southampton, Southampton, UK. Present address: ${ }^{71}$ Centre for Environment, Fisheries, \& Aquaculture Sciences (CEFAS), Lowestoft, UK. ${ }^{72}$ NOAA National Marine Fisheries Service, Southeast Regional Office, St. Petersburg, FL, USA. ${ }^{73}$ National Oceanic and Atmospheric Administration, Southeast Fisheries Science Center, Panama City Laboratory, Delwood Beach Road, Panama City, FL, USA. *e-mail: chrisbirdshark@gmail.com; trueman@noc.soton.ac.uk 


\section{Supplementary Information Guide}

Supplementary Figure 1: Simulated effect of trophic attenuation: The black points show two 12-month cycles of $\delta^{13} \mathrm{C}$ values of phytoplankton production simulated by the Magozzi, et al. ${ }^{1}$ NEMO MEDUSA isotopic extension for the North East Atlantic around the coast of west Ireland, a region characterised by a strong seasonal plankton bloom. Note the pronounced enrichment in $\delta^{13} \mathrm{C}$ values associated with bloom conditions in May-July. Dashed black line indicates the biomass-weighted annual average $\delta^{13} \mathrm{C}$ ром value, the relatively positive average $\delta^{13} \mathrm{C}$ value indicating that the bulk of all production occurs during bloom conditions. Animals feeding at successive trophic levels are simulated assuming constant feeding levels through the year and a trophic fractionation factor of 1 per mille. For trophic level (TL) 2 (red), an isotopic incorporation rate of 2 months was assumed, for TL 3 (blue) the incorporation rate is 4 months and for TL 4 (green) it is 6 months. Note that by TL 4 even the pronounced seasonal fluctuations in $\delta^{13} \mathrm{C}$ POM values of $>3$ per mille are essentially attenuated to less than 0.5 per mille through successive temporal smoothing, and the biomass weighted annual average is a reasonable approximation. In reality attenuation is likely to be more pronounced as feeding is not constant through the year but weighted to times of year with greater production.

Supplementary Figure 2: Latitudinal trends in mean $\delta^{13} \mathrm{C}$ values (with standard deviation bars) for shelf shark species (and one oceanic species: C. longimanus) that have the potential to migrate over multiple habitats (i.e either shelf and deep-sea habitats or shelf and oceanic habitats). Each point represents mean values for a population within an individual study with each colour corresponding to a different species. The latitudinal $\delta^{13} \mathrm{C}$ regression observed for oceanic shark muscle is also provided (dashed blue). 500 Monte Carlo iterations of the latitudinal trends in $\delta^{13} \mathrm{C}_{\mathrm{P}}$ observed in shelf sharks, considering the variance within each Longhurst Biogeographic Province (dark grey solid lines), and the latitudinal trends predicted for $\delta^{13} \mathrm{C}_{\mathrm{S}}$ with a trophic offset of 4.6 per mille (red solid lines - see Methods section and Figure 2).

Supplementary Figure 3: a): Boxes represent extent of environmental chlorophyll $a(\mathrm{Chl} a)$ and sea surface temperature (SST) data used to calculate latitudinal trends for each ha. Blue points represent locations of oceanic shark samples. Chl $a$ (b) and SST (c) for median sampling year, 2009, within oceanic waters. Bold vertical line represents median value for 
that latitudinal bin, box represents 50\% spread of the data and horizontal lines are the $95 \%$ confidence intervals. Latitude where abrupt shift in environmental data occurs shown with dashed grey line.

Supplementary Figure 4: Linear regressions for shark muscle $\delta^{13} \mathrm{C}\left(\delta^{13} \mathrm{C}_{\mathrm{S}}\right)$ (dashed line), corresponding predictions of planktonic $\delta^{13} \mathrm{C}\left(\delta^{13} \mathrm{Cp}\right)$ (solid line) with distance from the equator. Oceanic and deep-sea sharks have been combined within the "oceanic" plot. Individual points correspond to $\delta^{13} \mathrm{C}$ values from individual sharks from shelf (grey open circles), oceanic (blue open circles) and deep-sea (dark grey open circles) sharks. Confidence envelopes around the linear regressions (solid grey lines) reflect 500 Monte Carlo iterations considering the variance in each Longhurst Biogeographical Provinces, and applying a 4.6 per mille trophic offset (solid red lines). Maps represent sampling distributions overlaid on the $\delta^{13} \mathrm{C}$ isoscape from Figure 1.

Supplementary Table 1 (see Supplementary Table 1.xlsx): Primary habitat assignment for each shark species sampled within this study with corresponding paper provided within the reference. Asterisks denote species that are likely to migrate over multiple habitats and appear in Supplementary Figure 2.

Supplementary Table 2: List of trophic discrimination factors used to calculate trophic offset values for shark samples

Supplementary Table 3: Results from the most parsimonious generalised additive models (GAMS). Particulate organic carbon (POC) models describe POC $\ddot{a}^{13} \mathrm{C}$ as a function of distance from equator (DistEq). $\delta^{13} \mathrm{C}$ shark models describe ${ }^{13} \mathrm{C}$ trends in shark muscle as a function of DistEq, log total length (logTL) and depth (only for deep-sea sharks) where all measurements were available. SE is standard error, edf is estimated degrees of freedom and DE\% is the deviance explained by the explanatory variables. Difference is the difference between POC and shark models for the independent variables. 
The stable isotopic composition of a consumer's tissue reflects a time-integrated average of the composition of primary production fuelling the base of the food web, modified by isotopic fractionation during metabolism (i.e. preferential excretion of light isotopes and resulting enrichment of heavy isotopes in assimilated body proteins). We therefore consider four variables when predicting carbon stable isotopic compositions in shark tissues:

1. Variation in the isotopic composition of primary production between Longhurst Biogeographic Provinces.

2. Spatio-temporal variation of primary production within Longhurst Biogeographic Provinces.

3. Trophic fractionation between sharks and primary production.

4. Turnover rate of shark tissues, and implications for stable isotopes.

To determine the variation in the stable isotopic composition of carbon in primary production between Longhurst Biogeographic Provinces, we took biomass-weighted annual average predictions of $\delta^{13} \mathrm{C}$ values at one-degree intervals, and calculated the median of the annually averaged $\delta^{13} \mathrm{C}$ values within each biogeographic province. The biomass-weighted annual average simply weights the stable isotopic composition of diatoms and non-diatoms predicted at monthly intervals by the proportion of total annual production produced in that month ${ }^{1}$. Thus in temperate latitudes with seasonal plankton blooms, the biomass weighted average is closer to the isotopic composition of plankton grown under bloom conditions.

The use of annual (biomass weighted) average $\delta^{13} C_{P}$ values could in theory complicate spatial interpretations, however seasonal short-term variations in primary production $\delta^{13} \mathrm{C}$ values are attenuated through food chains, as the isotopic incorporation (turnover) rate increases with body size, and thus trophic level in size structured marine ecosystems. As an illustration, we simulate temporal fluctuations in the stable isotopic compositions of successive trophic levels sustained by phytoplankton in temperate latitudes characterised by extreme seasonal variations in $\delta^{13} \mathrm{C}_{\mathrm{P}}$ values (Supplementary Figure 1). We simulate the $\delta^{13} \mathrm{C}$ values in tissues of consumers at sequential trophic levels with isotopic equilibration rates of two, four, and six months respectively. By trophic level three (with an isotopic equilibration rate of six months, which is lower than predicted for most sharks), the amplitude of seasonal fluctuations in $\delta^{13} \mathrm{C}$ values is reduced from $>6$ per mille in phytoplankton to less than 2 per mille. Seasonal 
fluctuations in $\delta^{13} \mathrm{C}_{\mathrm{P}}$ values are therefore effectively smoothed through trophic attenuation, justifying the use of a constant biomass-weighted annual average reference value.

We considered the effect of spatial variability in $\delta^{13} C_{P}$ values within Longhurst Provinces by calculating the standard deviation and maximum range of $\delta^{13} \mathrm{C}$ values within each province. We estimated uncertainty around latitudinal trends in $\delta^{13} C_{P}$ values characterising Longhurst Provinces with a Monte Carlo simulation where we sampled $\delta^{13} C_{\mathrm{P}}$ values randomly from a Gaussian distribution taking the $\delta^{13} \mathrm{C}$ value in the latitudinal mid-point of the province as the mean and using the measured standard deviation.

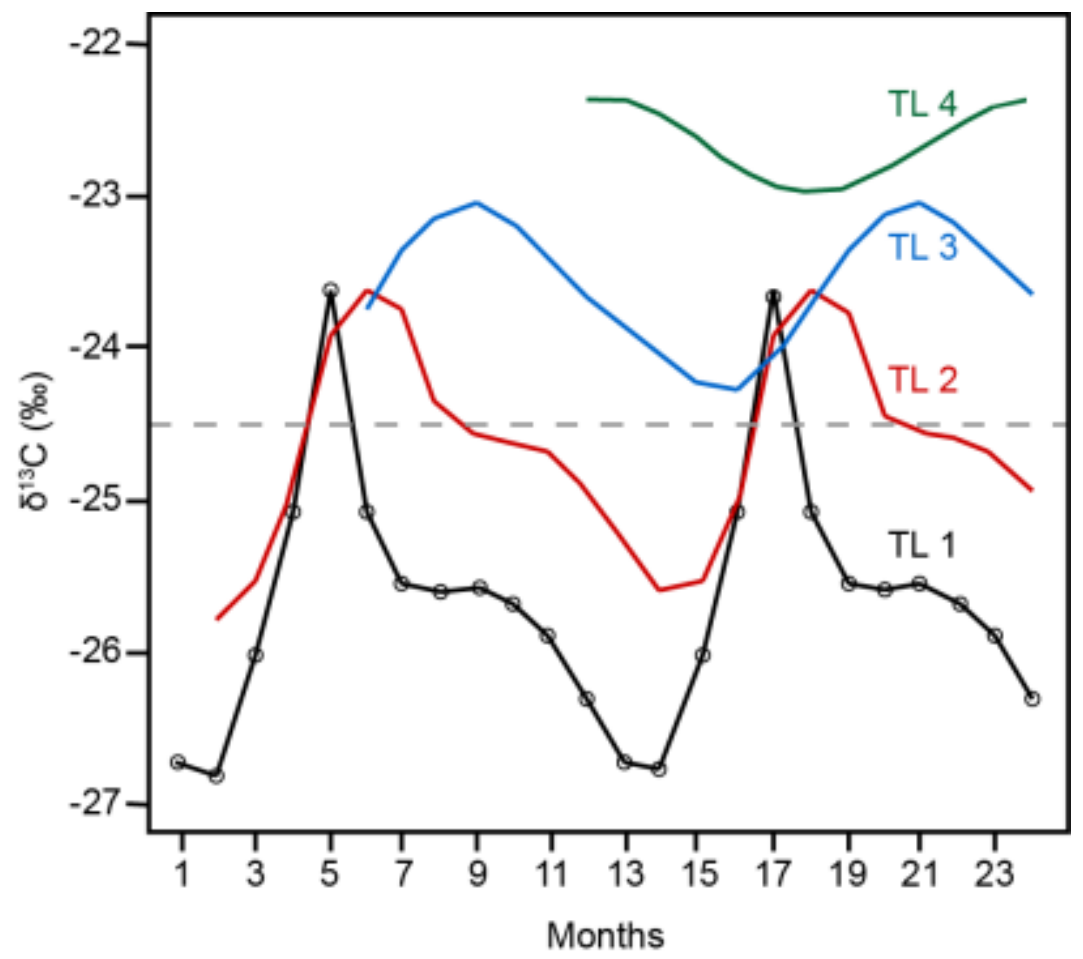

Supplementary Figure 1: Simulated effect of trophic attenuation: The black points show two 12month cycles of $\delta^{13} \mathrm{C}$ values of phytoplankton production simulated by the Magozzi, et al. ${ }^{1}$ NEMO MEDUSA isotopic extension for the North East Atlantic around the coast of west Ireland, a region characterised by a strong seasonal plankton bloom. Note the pronounced enrichment in $\delta^{13} \mathrm{C}$ values associated with bloom conditions in May-July. Dashed black line indicates the biomass-weighted annual average $\delta^{13} \mathrm{C}_{\text {POM }}$ value, the relatively positive average $\delta^{13} \mathrm{C}$ value indicating that the bulk of all production occurs during bloom conditions. Animals feeding at successive trophic levels are simulated assuming constant feeding levels through the year and a trophic fractionation factor of 1 per mille. For trophic level (TL) 2 (red), an isotopic incorporation rate of 2 months was assumed, for TL 3 (blue) the incorporation rate is 4 months and for TL 4 (green) it is 6 months. Note that by TL 4 even the pronounced seasonal fluctuations in $\delta^{13} \mathrm{C}$ POM values of $>3$ per mille are essentially attenuated to less than 0.5 per mille through successive temporal smoothing, and the biomass weighted annual average is a reasonable approximation. In reality attenuation is likely to be more pronounced as feeding is not constant through the year but weighted to times of year with greater production. 
The rate of isotopic turnover (the rate at which new atoms of carbon are assimilated from diet into tissues through growth and tissue turnover) varies between taxa and under differing conditions. We use as a first approximation scaling relationships between body size and turnover rate ${ }^{2}$ to estimate likely rates of turnover. Sharks with body masses between $10^{4} \mathrm{~g}$ and $10^{5} \mathrm{~g}$ are predicted to exhibit isotopic half-lives on the order of 100-200 days, with temperature influencing rates so that turnover will be greater at higher temperatures. Thus, a $10 \mathrm{~kg}$ shark moving between feeding sites separated by 10 degrees of latitude (reflecting 1.2 per mille difference in baseline $\delta^{13} \mathrm{C}$ values on average) would need to forage for 100 days in the new environment to express an isotopic shift in excess of 0.5 per mille. Isotopic turnover rate does, of course, limit the sensitivity to movement across isotopic gradients: animals foraging across isotopic gradients at timescales significantly shorter than isotopic turnover rates will form tissues with isotopic compositions reflecting a weighted average of the ingested food sources over the timescale of equilibration. If populations are comprised of individuals switching feeding between two isotopically-distinct resources, the median composition of the population will trend towards a value between the two sources, and the isotopic variance within the population will reduce as the rate at which the individuals switch resources (e.g. move between habitats) increases. Thus if individuals forage across a latitudinal range, the slope of the isotopic gradient reflected in the population mean of tissue isotopic compositions will reduce, the extent of any reduction depending on the relative proportion of tissues assimilated outside of the catch location during the period of isotopic equilibration, and the mean geographic distance between assimilation site and capture location.

Shelf sharks display population mean latitudinal slopes that are similar to that of local phytoplankton (Figure 2), implying little attenuation of isotopic gradients due to latitudinal mixing. Oceanic sharks, however, show shallow isotopic gradients that could, in theory, reflect either derivation of the majority of nutrients from restricted latitude, or foraging across large latitudinal gradients. In both cases derivation of nutrients with lower $\delta^{13} \mathrm{C}$ values (i.e. from higher latitudes) is needed to explain the shallow latitudinal gradients seen. Nutrients assimilated from regions characterised by primary production with higher $\delta^{13} \mathrm{C}$ (i.e. low latitude areas) must therefore be balanced by nutrients assimilated from isotopically depleted (high latitude) regions. Oceanic sharks are not commonly found in latitudes greater than c. $50^{\circ} \mathrm{N}$ or $\mathrm{S}$, limiting the potential to balance isotopically positive dietary sources, and we therefore infer that the majority of nutrients assimilated had a similar and relatively ${ }^{13} \mathrm{C}$ depleted isotopic composition, consistent with derivation from intermediate latitudes between 
c.30-50 degrees from the equator. The $\delta^{13} \mathrm{C}$ values of oceanic shark tissues captured at 10 degrees average around 17.5 per mille. A simple two component mass balance considering diet $\delta^{13} \mathrm{C}$ end member values estimated from phytoplankton models implies that between c. $65-100 \%$ of all nutrients must be derived from latitudes between 30 and 50 degrees.

\section{Interpretation of shelf variation}

Shelf dwelling shark populations display greater ranges in $\delta^{13} \mathrm{C}$ values than slope or pelagic dwelling sharks. This variation could be caused by increased spatial variation in regional phytoplankton baselines in coastal systems, or through increasing use of food webs supported by isotopically distinct sources.

Variations in $\delta^{13} \mathrm{C}$ values within Longhurst Biogeographic Provinces increase towards high latitudes that are characterised by steep latitudinal temperature gradients (Figure 2). Isotopic variation in shelf shark populations, however, is greater in tropical latitudes indicating that isotopic variability is not primarily controlled by spatial variation within the local biogeographic province.

Sharks are typically viewed as generalist consumers, however generalism may occur through individuals foraging across a wide range of resources or through populations comprised of individuals specialising on locally abundant, discrete sources. Individual generalism would tend to produce relatively low between-individual isotopic variability; therefore the high variance seen within populations of shelf sharks implies individual-level food web specialisation within the timescale of isotopic incorporation. Median $\delta^{13} \mathrm{C}$ values in shelf sharks populations are indistinguishable from those predicted for sharks feeding on local phytoplankton-dominated food webs. The null hypothesis that shelf sharks derive all carbon from local food webs supported by phytoplankton is therefore partially supported as latitudinal trends in $\delta^{13} \mathrm{C}$ values are indistinguishable from those predicted for phytoplankton, but the range in $\delta^{13} \mathrm{C}$ values observed in shelf sharks strongly implies additional utilisation of food webs characterised by high $\delta^{13} \mathrm{C}$ values.

The $\delta^{13} \mathrm{C}$ of shelf shark muscle muscles are relatively high compared to local phytoplankton at both low and high latitude ranges, likely as a consequence of a greater proportion of individual shelf sharks feeding on prey supported by primary production with higher $\delta^{13} \mathrm{C}$, or at a higher trophic level than currently prescribed. The very high $\delta^{13} \mathrm{C}$ values seen in some individual sharks (i.e. 5 per mille heavier than predicted) cannot realistically be explained 
through increased trophic level, and thus strongly imply derivation of a substantial proportion of their nutrients from more coastal food webs characterised by higher $\delta^{13} \mathrm{C}$, such as seagrasses, macrophytes, coral reefs, and/or terrestrially supported food webs ${ }^{3}$.

It is quite possible that individual or species-level differences in the consumption and routing of lipid-derived carbon into muscle protein contribute to the variance observed in $\delta^{13} \mathrm{C}$ values at all latitudes and in all shark groups. However, we know of no ecological or physiological reason to suspect either major differences in the degree and style of carbon routing between shelf and oceanic sharks or differential latitudinal effects of fasting or carbon routing between shelf and oceanic sharks.

Moving forward, the data compiled here will form the "Chondrichthyan Stable Isotope Data Project" and we invite the utilisation of these data and addition of new data to help build on the global geographic trends observed here. 


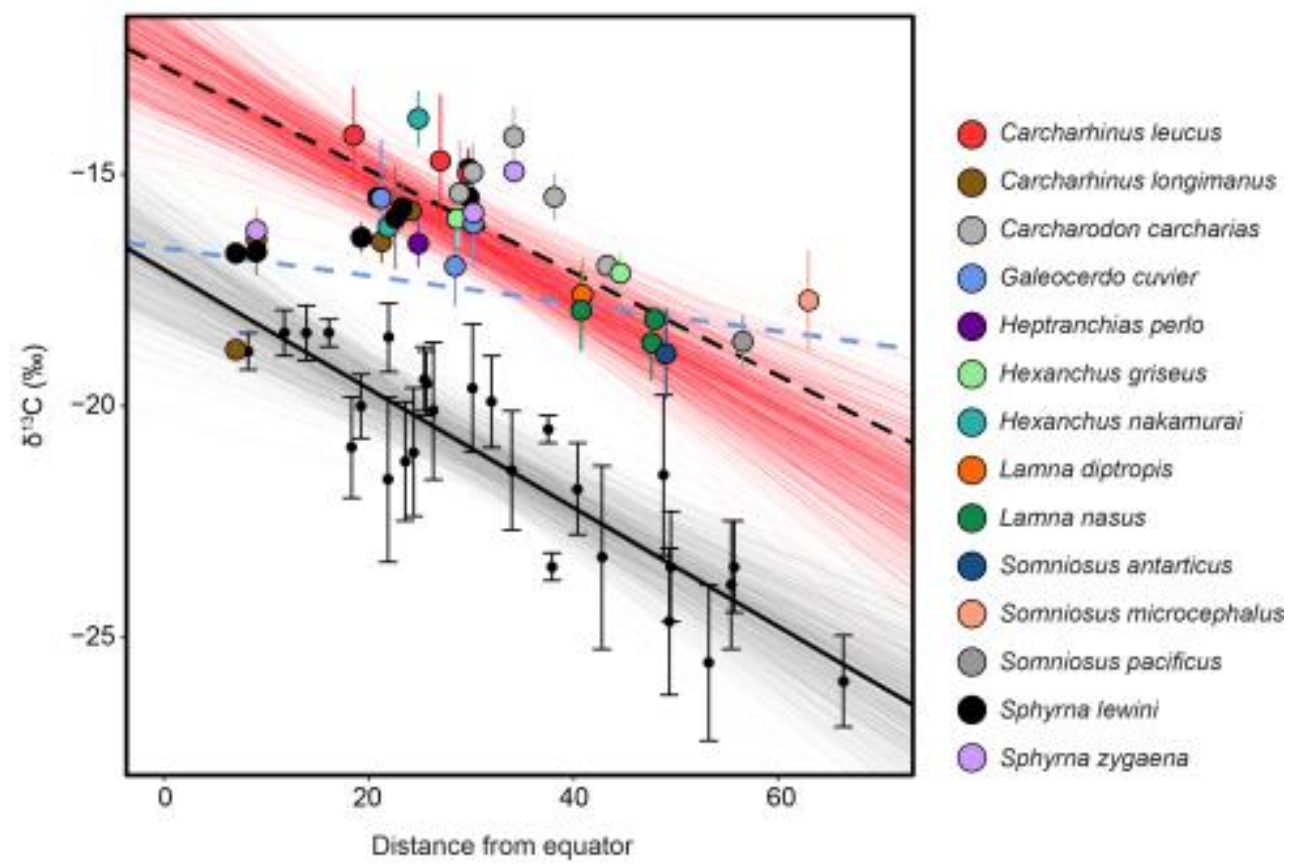

Supplementary Figure 2: Latitudinal trends in mean $\delta^{13} \mathrm{C}$ values (with standard deviation bars) for shelf shark species (and one oceanic species: $C$. longimanus) that have the potential to migrate over multiple habitats (i.e either shelf and deep-sea habitats or shelf and oceanic habitats). Each point represents mean values for a population within an individual study with each colour corresponding to a different species. The latitudinal $\delta^{13} \mathrm{C}$ regression observed for oceanic shark muscle is also provided (dashed blue). 500 Monte Carlo iterations of the latitudinal trends in $\delta^{13} \mathrm{C}_{\mathrm{P}}$ observed in shelf sharks, considering the variance within each Longhurst Biogeographic Province (dark grey solid lines), and the latitudinal trends predicted for $\delta^{13} \mathrm{C}_{S}$ with a trophic offset of 4.6 per mille (red solid lines - see Methods section and Figure 2). 

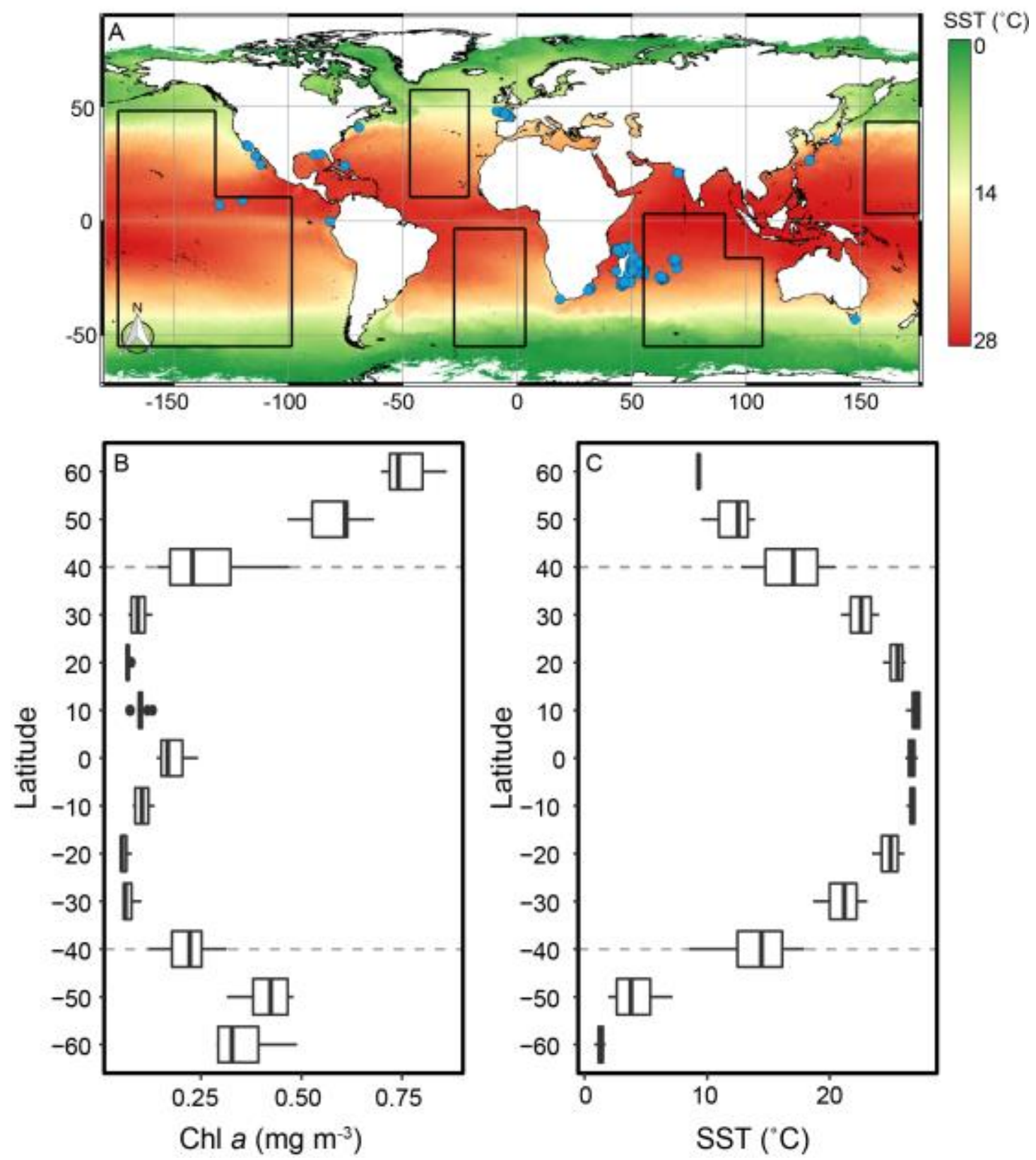

Supplementary Figure 3: a): Boxes represent extent of environmental chlorophyll $a(\mathrm{Chl} a)$ and sea surface temperature (SST) data used to calculate latitudinal trends for each ha. Blue points represent locations of oceanic shark samples. Chl $a$ (b) and SST (c) for median sampling year, 2009, within oceanic waters. Bold vertical line represents median value for that latitudinal bin, box represents 50\% spread of the data and horizontal lines are the $95 \%$ confidence intervals. Latitude where abrupt shift in environmental data occurs shown with dashed grey line. 


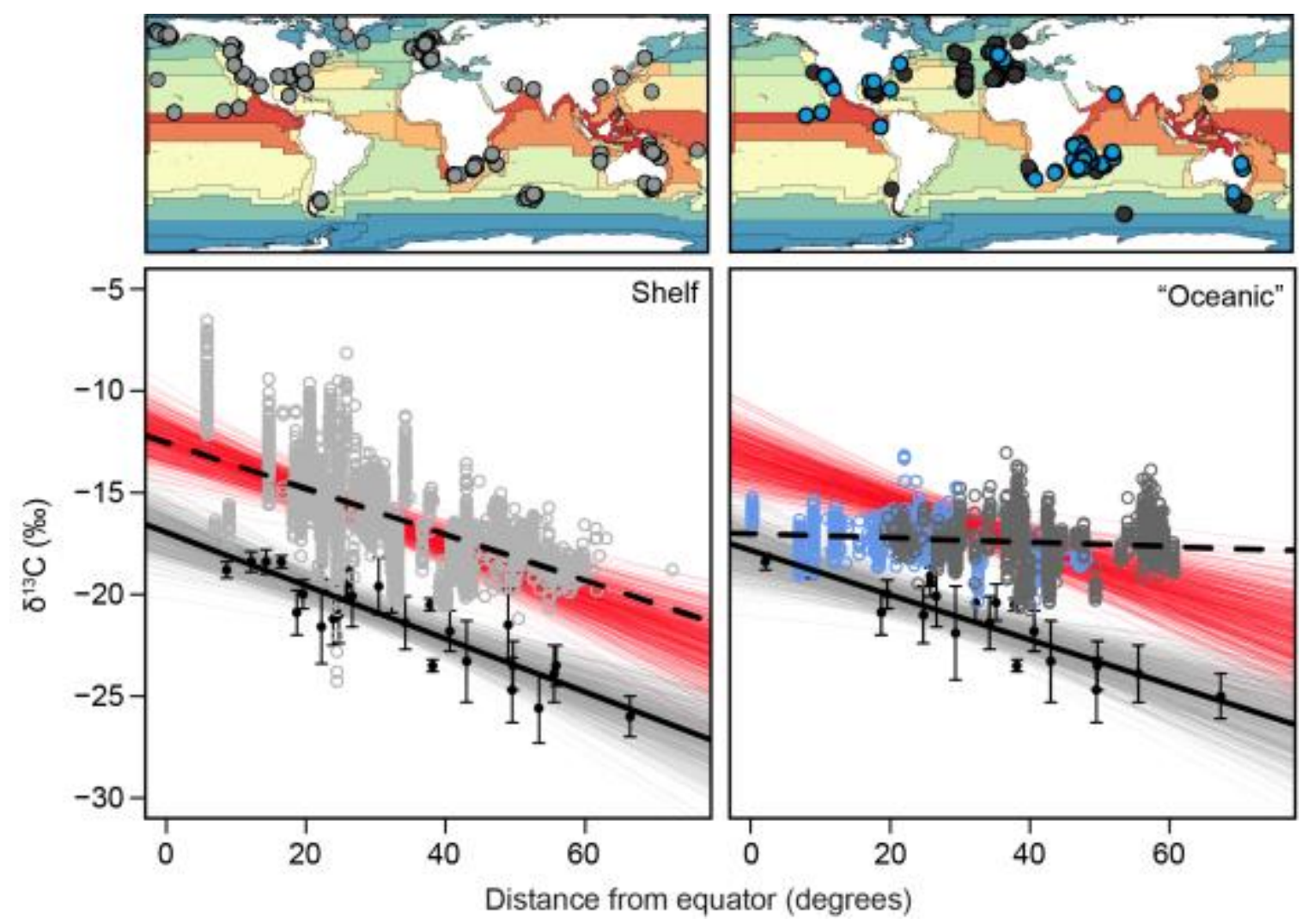

Supplementary Figure 4: Linear regressions for shark muscle $\delta^{13} \mathrm{C}\left(\delta^{13} \mathrm{Cs}\right)$ (dashed line), corresponding predictions of planktonic $\delta^{13} \mathrm{C}\left(\delta^{13} \mathrm{C}_{\mathrm{P}}\right)$ (solid line) with distance from the equator. Oceanic and deep-sea sharks have been combined within the "oceanic" plot. Individual points correspond to $\delta^{13} \mathrm{C}$ values from individual sharks from shelf (grey open circles), oceanic (blue open circles) and deep-sea (dark grey open circles) sharks. Confidence envelopes around the linear regressions (solid grey lines) reflect 500 Monte Carlo iterations considering the variance in each Longhurst Biogeographical Provinces, and applying a 4.6 per mille trophic offset (solid red lines). Maps represent sampling distributions overlaid on the $\delta^{13} \mathrm{C}$ isoscape from Figure 1. 
Supplementary Table 1 (Please see attached Supplementary_Tables.xlsx): Primary

habitat assignment for each shark species sampled within this study with corresponding paper provided. Asterisks denote species that are likely to migrate over multiple habitats and appear in Supplementary Figure 2.

Supplementary Table 2: List of trophic discrimination factors used to calculate trophic offset values for shark samples.

\begin{tabular}{ccc}
\hline Species & $\Delta^{13} \mathrm{C}(\mathrm{SD}), \% 0$ & Reference \\
\hline Scyliorhinus canicula & $0.80(0.10)$ & 59 \\
Carcharias taurus \& & $0.84(0.23)$ & 60 \\
Negaprion brevirostris & & \\
Triakis semifasciata & 1.00 & 61 \\
Triakis semifasciata & $1.70(0.50)$ & 62 \\
\hline Mean & 1.10 \\
\hline
\end{tabular}


Supplementary Table 3: Results from the most parsimonious generalised additive models (GAMs). Particulate organic carbon (POC) models describe $\mathrm{POC} \delta^{13} \mathrm{C}$ as a function of distance from equator (DistEq). $\delta^{13} \mathrm{C}$ shark models describe $\delta^{13} \mathrm{C}$ trends in shark muscle as a function of DistEq, log total length (logTL) and depth (only for deep-sea sharks) where all measurements were available. SE is standard error, edf is estimated degrees of freedom and $\mathrm{DE} \%$ is the deviance explained by the explanatory variables. Difference is the difference between POC and shark models for the independent variables.

\begin{tabular}{|c|c|c|c|c|c|c|c|c|c|c|c|c|c|}
\hline \multirow[b]{2}{*}{ Habitat } & \multirow[b]{2}{*}{ Smooth Term } & & \multicolumn{4}{|c|}{ Parametric Coefficients } & \multicolumn{4}{|c|}{ Significance of smooth terms } & \multirow[b]{2}{*}{$\mathrm{n}$} & \multirow[b]{2}{*}{$\mathrm{DE} \%$} & \multirow[b]{2}{*}{ AIC } \\
\hline & & & Estimate & S.E & $\mathrm{t}$ & $\operatorname{Pr}(>|t|)$ & edf & Ref.df & $\mathrm{F}$ & $\mathrm{p}$ value & & & \\
\hline \multirow[t]{7}{*}{ Shelf } & POC DistEq & & -20.89 & 0.02 & -1008 & $<0.001$ & 2.00 & 2.00 & 2969.00 & $<0.001$ & 3029 & 66.3 & 9397 \\
\hline & DistEq & & -16.17 & 0.03 & -523 & $<0.001$ & 2.00 & 2.00 & 1098.00 & $<0.001$ & 3029 & 42.0 & 11824 \\
\hline & $\log T L$ & & -16.17 & 0.04 & -404 & $<0.001$ & 1.91 & 1.99 & 45.66 & $<0.001$ & 3029 & 3.1 & 13381 \\
\hline & DistEq $\times \log T$ & & -16.17 & 0.03 & -545 & $<0.001$ & & & & $<0.001$ & 3029 & 46.7 & 11570 \\
\hline & & DistEq & & & & & 2.00 & 2.00 & 1248.30 & $<0.001$ & & & \\
\hline & & $\log T L$ & & & & & 1.00 & 1.00 & 267.50 & $<0.001$ & DIFF & & \\
\hline & & & & & & & & & & & & 19.6 & \\
\hline \multirow[t]{7}{*}{ Oceanic } & $\mathrm{POC} \sim$ DistEq & & -20.24 & 0.02 & -811 & $<0.001$ & 2.00 & 2.00 & 1918.00 & $<0.001$ & 651 & 85.6 & 1264 \\
\hline & DistEq & & -17.22 & 0.03 & -495 & $<0.001$ & 1.83 & 1.97 & 79.37 & $<0.001$ & 651 & 20.2 & 1697 \\
\hline & $\log T L$ & & -17.22 & 0.04 & -453 & $<0.001$ & 1.97 & 2.00 & 15.51 & $<0.001$ & 651 & 4.8 & 1813 \\
\hline & DistEq $\times \log T$ & & -17.22 & 0.03 & -499 & $<0.001$ & & & & & 651 & 21.7 & 1689 \\
\hline & & DistEq & & & & & 1.87 & 1.98 & 68.24 & $<0.001$ & & & \\
\hline & & $\log T L$ & & & & & 1.83 & 1.97 & 5.18 & 0.004 & & & \\
\hline & & & & & & & & & & & DIFF & 63.9 & \\
\hline \multirow{13}{*}{ Bathyal } & POC DistEq & & -21.75 & 0.03 & -838 & $<0.001$ & 1.98 & 2.00 & 1604.00 & $<0.001$ & 1452 & 68.8 & 4091 \\
\hline & DistEq & & -17.42 & 0.03 & -598 & $<0.001$ & 1.98 & 2.00 & 22.89 & $<0.001$ & 1452 & 3.1 & 4431 \\
\hline & $\log T L$ & & -17.42 & 0.03 & -681 & $<0.001$ & 1.97 & 2.00 & 248.00 & $<0.001$ & 1452 & 25.3 & 4052 \\
\hline & Depth & & 17.42 & 0.03 & -598 & $<0.001$ & 1.97 & 2.00 & 138.00 & $<0.001$ & 1452 & 17.6 & 3764 \\
\hline & DistEq $x \log T$ & & -17.42 & 0.03 & -695 & $<0.001$ & & & & & 1452 & 28.5 & 3994 \\
\hline & & DistEq & & & & & 1.99 & 2.00 & 31.61 & $<0.001$ & & & \\
\hline & & $\log T L$ & & & & & 1.99 & 2.00 & 255.40 & $<0.001$ & & & \\
\hline & & & & & & & & & & & DIFF & 40.3 & \\
\hline & DistEq $\times \log T L \times$ & Depth & -17.42 & 0.03 & -667 & $<0.001$ & & & & & $145 \overline{2}$ & 34.0 & 3994 \\
\hline & & DistEq & & & & & 1.97 & 2.00 & 10.23 & $<0.001$ & & & \\
\hline & & $\log T \mid$ & & & & & 1.96 & 2.00 & 121.23 & $<2 \mathrm{E}-16$ & & & \\
\hline & & Depth & & & & & 1.81 & 1.96 & 38.82 & $<2 \mathrm{E}-16$ & & & \\
\hline & & & & & & & & & & & DIFF & 34.8 & \\
\hline
\end{tabular}


References:

1 Magozzi, S., Yool, A., Vander Zanden, H. B., Wunder, M. B. \& Trueman, C. N. Using ocean models to predict spatial and temporal variation in marine carbon isotopes. Ecosphere 8, e01763 (2017).

2 Thomas, S. M. \& Crowther, T. W. Predicting rates of isotopic turnover across the animal kingdom: a synthesis of existing data. Journal of Animal Ecology 84, 861-870 (2015).

3 Fry, B. \& Sherr, E. B. in Stable Isotopes in Ecological Research (eds P. W. Rundel, J. R. Ehleringer, \& K. A. Nagy) 196-229 (Springer New York, 1989).

4 Abrantes, K. G. \& Barnett, A. Intrapopulation variations in diet and habitat use in a marine apex predator, the broadnose sevengill shark Notorynchus cepedianus. Marine Ecology Progress Series 442, 133-148 (2011).

5 Frisch, A. J. et al. Reassessing the trophic role of reef sharks as apex predators on coral reefs. Coral Reefs 35, 459-472 (2016).

6 Blanchard, J. L., Law, R., Castle, M. D. \& Jennings, S. Coupled energy pathways and the resilience of size-structured food webs. Theoretical Ecology 4, 289-300 (2011).

7 Hussey, N. E. et al. Expanded trophic complexity among large sharks. Food Webs 4, 1-7 (2015).

8 Kinney, M. J., Hussey, N. E., Fisk, A. T., Tobin, A. J. \& Simpfendorfer, C. A. Communal or competitive? Stable isotope analysis provides evidence of resource partitioning within a communal shark nursery. Marine Ecology Progress Series 439, 263-276 (2011).

9 Vaudo, J. J. \& Heithaus, M. R. Dietary niche overlap in a nearshore elasmobranch mesopredator community. Marine Ecology Progress Series 425, 247-260 (2011).

10 Papastamatiou, Y. P., Meyer, C. G., Kosaki, R. K., Wallsgrove, N. J. \& Popp, B. N. Movements and foraging of predators associated with mesophotic coral reefs and their potential for linking ecological habitats. Marine Ecology Progress Series 521, 155-170 (2015).

11 Daly, R., Froneman, P. W. \& Smale, M. J. Comparative feeding ecology of bull sharks Carcharhinus leucas in the coastal waters of the southwest indian ocean inferred from stable isotope analysis. PLOS ONE 8, e78229 (2013).

12 Matich, P., Heithaus, M. R. \& Layman, C. A. Contrasting patterns of individual specialization and trophic coupling in two marine apex predators. Journal of Animal Ecology 80, 294-305 (2011).

13 Plumlee, J. D. \& Wells, R. J. D. Feeding ecology of three coastal shark species in the northwest Gulf of Mexico. Marine Ecology Progress Series 550, 163-174 (2016).

14 Papastamatiou, Y. P., Friedlander, A. M., Caselle, J. E. \& Lowe, C. G. Longterm movement patterns and trophic ecology of blacktip reef sharks (Carcharhinus melanopterus) at Palmyra Atoll. Journal of Experimental Marine Biology and Ecology 386, 94-102 (2010).

15 Speed, C. W. et al. Trophic ecology of reef sharks determined using stable isotopes and telemetry. Coral Reefs 31, 357-367 (2012). 
16 Maljković, A. \& Côté, I. M. Effects of tourism-related provisioning on the trophic signatures and movement patterns of an apex predator, the Caribbean reef shark. Biological Conservation 144, 859-865 (2011).

17 Tilley, A., López-Angarita, J. \& Turner, J. R. Diet reconstruction and resource partitioning of a Caribbean marine mesopredator using stable isotope bayesian modelling. PLOS ONE 8, e79560 (2013).

18 Shiffman, D. S, et al. Feeding ecology of the sandbar shark in south carolina estuaries revealed through $\delta^{13} \mathrm{C}$ and $\delta^{15} \mathrm{~N}$ stable isotope analysis, Marine and Coastal Fisheries 6, 156-169 (2014)

19 Churchill, D. A. et al. Trophic interactions of common elasmobranchs in deep-sea communities of the gulf of mexico revealed through stable isotope and stomach content analysis. Deep Sea Research Part II: Topical Studies in Oceanography 115, 92-102 (2015).

20 Borrell, A., Cardona, L., Kumarran, R. P. \& Aguilar, A. Trophic ecology of elasmobranchs caught off Gujarat, India, as inferred from stable isotopes. ICES Journal of Marine Science 68, 547-555 (2010).

21 Carlisle, A. B. et al. Using stable isotope analysis to understand the migration and trophic ecology of northeastern Pacific white sharks Carcharodon carcharias, PLoS ONE 7, e30492 (2012).

22 Malpica-Cruz, L., Herzka, S. Z., Sosa-Nishizaki, O. \& Escobedo-Olvera, M. A. Tissue-specific stable isotope ratios of shortfin mako (Isurus oxyrinchus) and white (Carcharodon carcharias) sharks as indicators of size-based differences in foraging habitat and trophic level. Fisheries Oceanography, 22, 429-445 (2013).

23 Wai, T.-C. et al. Monsoons and habitat influence trophic pathways and the importance of terrestrial-marine linkages for estuary sharks. Ecosphere 3, 1-31 (2012).

24 Pethybridge, H., Daley, R. K. \& Nichols, P. D. Diet of demersal sharks and chimaeras inferred by fatty acid profiles and stomach content analysis. Journal of Experimental Marine Biology and Ecology 409, 290-299 (2011).

25 Chouvelon, T. et al. Enhanced bioaccumulation of mercury in deep-sea fauna from the Bay of Biscay (North-east Atlantic) in relation to trophic positions identified by analysis of carbon and nitrogen stable isotopes. Deep Sea Research Part I: Oceanographic Research Papers 65, 113-124 (2012).

26 Kopp, D., Lefebvre, S., Cachera, M., Villanueva, M. C. \& Ernande, B. Reorganization of a marine trophic network along an inshore-offshore gradient due to stronger pelagic-benthic coupling in coastal areas. Progress in Oceanography 130, 157-171 (2015).

27 Shipley, O. N. et al. Stable isotopes reveal food web dynamics of a datapoor deep-sea island slope community. Food Webs 10, 22-25 (2017).

28 Carlisle, A. B. et al. Stable isotope analysis of vertebrae reveals ontogenetic changes in habitat in an endothermic pelagic shark. Proceedings of the Royal Society of London B: Biological Sciences 282, 20141446 (2015).

29 Cherel, Y., Xavier, J. C., de Grissac, S., Trouvé, C. \& Weimerskirch, H. Feeding ecology, isotopic niche, and ingestion of fishery-related items of the wandering albatross Diomedea exulans at Kerguelen and Crozet Islands. Marine Ecology Progress Series 565, 197-215 (2017). 
30 Teffer, A. K., Staudinger, M. D., Taylor, D. L. \& Juanes, F. Trophic influences on mercury accumulation in top pelagic predators from offshore new england waters of the northwest Atlantic ocean. Marine Environmental Research 101, 124-134 (2014).

31 Kiszka, J. J. et al. Trophic ecology of common elasmobranchs exploited by artisanal shark fisheries off south-western Madagascar, 23, 29-38 (2014).

32 Chouvelon, T. et al. Revisiting the use of $\delta^{15} \mathrm{~N}$ in meso-scale studies of marine food webs by considering spatio-temporal variations in stable isotopic signatures - the case of an open ecosystem: The Bay of Biscay (North-east Atlantic). Progress in Oceanography 101, 92-105 (2012).

33 Raoult, V., Gaston, T. F. \& Williamson, J. E. Not all sawsharks are equal: Species of co-existing sawsharks show plasticity in trophic consumption both within and between species. Canadian Journal of Fisheries and Aquatic Sciences 72, 1769-1775 (2015).

34 Al-Reasi, H. A., Ababneh, F. A. \& Lean, D. R. Evaluating mercury biomagnification in fish from a tropical marine environment using stable isotopes $\left(\delta^{13} \mathrm{C}\right.$ and $\left.\delta^{15} \mathrm{~N}\right)$. Environmental Toxicology and Chemistry 26, 1572-1581 (2007).

35 Munroe, S. E. M., Heupel, M. R., Fisk, A. T., Logan, M. \& Simpfendorfer, C. A. Regional movement patterns of a small-bodied shark revealed by stableisotope analysis. Journal of Fish Biology 86, 1567-1587 (2015).

36 Ciancio, J. E., Pascual, M. A., Botto, F., Frere, E. \& Iribarne, O. Trophic relationships of exotic anadromous salmonids in the southern Patagonian shelf as inferred from stable isotopes. Limnology and Oceanography 53, 788 - 798 (2008).

37 Caut, S., Jowers, M. J., Michel, L., Lepoint, G. \& Fisk, A. T. Diet-and tissuespecific incorporation of isotopes in the shark Scyliorhinus stellaris, a North Sea mesopredator. Marine Ecology Progress Series 492, 185-198 (2013).

38 Cresson, P. et al. Mercury in organisms from the northwestern Mediterranean slope: Importance of food sources. Science of The Total Environment 497-498, 229-238 (2014).

39 Valls, M. et al. Structure and dynamics of food webs in the water column on shelf and slope grounds of the western Mediterranean. Journal of Marine Systems 138, 171-181 (2014).

40 Hansen, J. H., Hedeholm, R. B., Sünksen, K., Christensen, J. T. \& Grønkjær, P. Spatial variability of carbon $\left(\delta^{13} \mathrm{C}\right)$ and nitrogen $\left(\delta^{15} \mathrm{~N}\right)$ stable isotope ratios in an Arctic marine food web. Marine Ecology Progress Series 467, 47-59 (2012).

41 Courtney, D. \& Foy, R. Pacific sleeper shark Somniosus pacificus trophic ecology in the eastern north Pacific Ocean inferred from nitrogen and carbon stable-isotope ratios and diet. Journal of Fish Biology 80, 15081545 (2012).

42 Bethea, D. M., Carlson, J. K., Hollensead, L. D., Papastamatiou, Y. P. \& Graham, B. S. A comparison of the foraging ecology and bioenergetics of the early life-stages of two sympatric hammerhead sharks. Bulletin of Marine Science 87, 873-889 (2011).

43 Kiszka, J. J. et al. Plasticity of trophic interactions among sharks from the oceanic south-western Indian Ocean revealed by stable isotope and 
mercury analyses. Deep Sea Research Part I: Oceanographic Research Papers 96, 49-58 (2015).

44 Rojas, Y. E. T. et al. Feeding grounds of juvenile scalloped hammerhead sharks (Sphyrna lewini) in the south-eastern Gulf of California.

Hydrobiologia 726, 81-94 (2014).

45 Li, Y., Gong, Y., Chen, X., Dai, X. \& Zhu, J. Trophic ecology of sharks in the mid-east Pacific Ocean inferred from stable isotopes. Journal of Ocean University of China 13, 278-282 (2014).

46 Li, Y., Zhang, Y. \& Dai, X. Trophic interactions among pelagic sharks and large predatory teleosts in the northeast central Pacific. Journal of Experimental Marine Biology and Ecology 483, 97-103 (2016).

47 Endo, T. et al. Contamination levels of mercury in the muscle of female and male spiny dogfishes (Squalus acanthias) caught off the coast of Japan. Chemosphere 77, 1333-1337 (2009).

48 Reum, J. C. \& Essington, T. E. Spatial and seasonal variation in $\delta^{15} \mathrm{~N}$ and $\delta^{13} \mathrm{C}$ values in a mesopredator shark, Squalus suckleyi, revealed through multitissue analyses. Marine biology 160, 399-411 (2013).

49 Polo-Silva, C., Newsome, S. D., Galván-Magaña, F., Grijalba-Bendeck, M. \& Sanjuan-Muñoz, A. Trophic shift in the diet of the pelagic thresher shark based on stomach contents and stable isotope analyses. Marine Biology Research 9, 958-971 (2013).

50 Radabaugh, K. R., Hollander, D. J. \& Peebles, E. B. Seasonal $\delta^{13} \mathrm{C}$ and $\delta^{15} \mathrm{~N}$ isoscapes of fish populations along a continental shelf trophic gradient. Continental Shelf Research 68, 112-122 (2013).

51 Madigan, D. J. et al. Diet shift and site-fidelity of oceanic whitetip sharks Carcharhinus longimanus along the great Bahama bank. Marine Ecology Progress Series 529 (2015).

52 Madigan, D. J. et al. Stable isotope analysis challenges wasp-waist food web assumptions in an upwelling pelagic ecosystem. Scientific Reports $\mathbf{2}$, e654 (2012).

53 Trueman, C. N., Johnston, G., O'Hea, B. \& MacKenzie, K. M. Trophic interactions of fish communities at midwater depths enhance long-term carbon storage and benthic production on continental slopes. Proceedings of the Royal Society B: Biological Sciences 281, p. 20140669 (2014).

54 Boyle, M. D., Ebert, D. A. \& Cailliet, G. M. Stable-isotope analysis of a deepsea benthic-fish assemblage: Evidence of an enriched benthic food web. Journal of Fish Biology 80, 1485-1507 (2012).

55 Lopez, S., Zapata-Hernández, G., Bustamante, C., Sellanes, J. \& Meléndez, R. Trophic ecology of the dusky catshark Bythaelurus canescens (Günther, 1878)(Chondrychthyes: Scyliorhinidae) in the southeast Pacific Ocean. Journal of Applied Ichthyology 29, 751-756 (2013).

56 Iitembu, J. A. \& Richoux, N. B. Trophic relationships of hake (Merluccius capensis and M. paradoxus) and sharks (Centrophorus squamosus, Deania calcea and D. profundorum) in the northern (Namibia) Benguela Current region. African Zoology, 1-7 (2015).

57 Newman, M., Xu, X., Cotton, C. \& Tom, K. High mercury concentrations reflect trophic ecology of three deep-water chondrichthyans. Archives of Environmental Contamination and Toxicology 60, 618-625 (2011). 
58 Colaço, A., Giacomello, E., Porteiro, F. \& Menezes, G. M. Trophodynamic studies on the Condor Seamount (Azores, Portugal, north Atlantic). Deep Sea Research Part II: Topical Studies in Oceanography 98, Part A, 178-189 (2013).

59 Caut, S., Angulo, E. \& Courchamp, F. Variation in discrimination factors $\left(\delta^{15} \mathrm{~N}\right.$ and $\left.\delta^{13} \mathrm{C}\right)$ : The effect of diet isotopic values and applications for diet reconstruction. Journal of Applied Ecology 46, 443-453 (2009).

60 Hussey, N. E., Brush, J., McCarthy, I. D. \& Fisk, A. T. $\delta^{15} \mathrm{~N}$ and $\delta^{13} \mathrm{C}$ diettissue discrimination factors for large sharks under semi-controlled conditions. Comparative Biochemistry and Physiology Part A: Molecular \& Integrative Physiology 155, 445-453 (2010).

61 Malpica-Cruz, L., Herzka, S. Z., Sosa-Nishizaki, O., Lazo, J. P. \& Trudel, M. Tissue-specific isotope trophic discrimination factors and turnover rates in a marine elasmobranch: Empirical and modeling results. Canadian Journal of Fisheries and Aquatic Sciences 69, 551-564 (2012).

62 Kim, S. L. et al. Carbon and nitrogen discrimination factors for elasmobranch soft tissues based on a long-term controlled feeding study. Environmental Biology of Fishes 95, 37-52 (2012). 